\title{
Heróis velhos em uruguaios jovens
}

\author{
Federico Alvez Cavanna \\ Gabriel Quirici
}

CAVANNA, F.A., and QUIRICI, G. Heróis velhos em uruguaios jovens. In: CERRI, L.F., ed. Os jovens e a História: Brasil e América do Sul [online]. Ponta Grossa: Editora UEPG, 2018, pp. 163185. ISBN: 978-85-7798-248-6. https://doi.org/10.7476/9788577982486.0008.

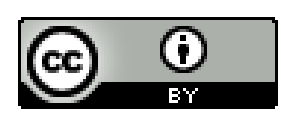

All the contents of this work, except where otherwise noted, is licensed under a Creative Commons Attribution $\underline{4.0 \text { International license. }}$

Todo o conteúdo deste trabalho, exceto quando houver ressalva, é publicado sob a licença Creative Commons Atribição 4.0.

Todo el contenido de esta obra, excepto donde se indique lo contrario, está bajo licencia de la licencia Creative Commons Reconocimento 4.0. 


\section{HERÓIS VELHOS EM URUGUAIOS JOVENS}

Federico Alvez Cavanna

Gabriel Quirici

O presente artigo analisa o segmento das respostas da pesquisa Jovens e a História no Mercosul, na sua amostra do Uruguai, em escolas do âmbito público e também do particular, da capital e do interior, com o objetivo de sondar diversos aspectos do ensino e da aprendizagem da disciplina.

Neste caso, entre os muitos dados que a enquete oferece, o foco foi colocado nas opções relacionadas com os heróis históricos nacionais indicados pelos jovens uruguaios. Na primeira parte do texto, descrevem-se os dados obtidos e formulam-se alguns critérios para sua análise e síntese. $\mathrm{Na}$ segunda seção, são propostas algumas reflexões disciplinares e didáticas, em que os dados sugerem como convite para pensar as relações entre a História ensinada e os imaginários coletivos.

\section{ARTIGAS, A POLÍTICA E O FUTEBOL}

O questionário realizado em 228 (duzentos e vinte e oito) casos oferecia a oportunidade de preencher três linhas vazias com o nome de três heróis nacionais, por ordem de importância para o estudante. No total, representam 684 (seiscentos e oitenta e quatro) respostas possíveis, com diferentes níveis de importância, de 1 a 3, em ordem hierárquica decrescente.

A enquete foi realizada com estudantes de 15 anos, no ano de 2012, permitindo rastrear diferentes percepções de como é assimilada, pelos adolescentes, a palavra herói, em um contexto de escolarização determinado pelo ensino da História. É importante lembrar a influência do contexto geral de apresentação da enquete para os jovens: ela foi aplicada com docentes de História em suas aulas no âmbito escolar e explicando que, entre os seus objetivos, estava a pesquisa sobre a História ensinada.

A multiplicidade de respostas foi interessante. No entanto, é possível extrair alguns comportamentos gerais suscetíveis de serem analisados 
para refletir sobre a mitologia histórica escolarizada e sua relação com a cultura histórica uruguaia.

Desde já, adiantamos que mergulhar nos resultados da enquete significa encontrar uma estimulante variedade: como casos (isolados e irreverentes) em que as três respostas coincidem com super-heróis de história em quadrinhos (Batman, Superman e Flash), outros colocaram seus pais, e as mais repetidas são as que apresentam uma visão quase de história oficial, em que os heróis escolhidos foram o panteão político-nacional (Artigas, Lavalleja e Rivera). No meio desses extremos, observam-se alguns mixes entre figuras políticas da História (com absoluto predomínio de Artigas), futebolistas destacados em nível internacional, políticos do presente e, também, figuras da cultura (Mario Benedetti, Jorge Drexler).

Para sintetizar os dados, foram consideradas as decisões metodológicas que seguem.

1. Em primeiro lugar, analisam-se os casos de respostas negativas ou vazias;

2. Em seguida, descrevem-se os resultados dos heróis mencionados no total da amostra, para elaborar um ranking de Heróis escolarizados;

3. Por fim, analisam-se as respostas por estudante, com a finalidade de encontrar padrões de resposta individuais.

Para a construção do ranking de heróis escolarizados foram consideradas todas as respostas, com exceção das vazias. No total, foram 228 (duzentos e vinte e oito) estudantes que tinham 684 (seiscentos e oitenta e quatro) células para completar. Uma vez terminada a enquete, as células efetivamente completadas (com heróis escritos) foram 506 (quinhentos e seis), e com estas últimas construímos o ranking no total. No entanto, para a identificação de possíveis padrões de resposta, elas foram analisadas individualmente. Sendo assim, os 100\%, neste corte, corresponde aos 228 (duzentos e vinte e oito) alunos que responderam. 


\section{SEM HERÓIS}

Pouco menos de $25 \%$ das células foi completado com a palavra nenhum herói, ou deixadas em branco. Com a particularidade que aqueles que escreveram explicitamente nenhum [sic], fizeram isso nas três células, deixando claro sua posição em não destacar nenhum herói.

Por outra parte, observa-se que as células em branco vão crescendo na medida em que o nível de importância hierárquica vai diminuindo. Muitos estudantes (18\%) preencheram somente a primeira caixinha/lacuna, e deixaram vazios os dois restantes.

Sendo assim, poderíamos afirmar, com segurança, que desses $25 \%$ de ausência de heróis na tabela, somente $5 \%$ não as completa ou manifesta não ter heróis explicitamente. Enquanto o restante $20 \%$ somente assinalou um herói, o que poderia ser interpretado como falta de significado substantivo para o estudante, de parte da temática proposta.

Resumindo, um quarto das respostas da amostra dá a impressão de que o tema não lhes foi relevante e, dentro deste um quarto, um pequeno núcleo duro, de $5 \%$, não respondeu ou somente afirmou sua resposta utilizando a palavra nenhum.

\section{RESULTADOS INICIAIS: HERÓI POR HERÓI}

Abordamos, agora, a descrição dos resultados daqueles que escreveram seus heróis e apresentamos os resultados em nível individual e, posteriormente, certos padrões de respostas combinadas, que permitem analisar com mais detalhes a enquete.

Entre os que escreveram minimamente um herói, o ranking de celebridades mencionadas foi o seguinte: José Artigas: 30\%; José Pedro Varela: 11\%; Lavalleja: 8\%; Rivera: 5\%; Aparicio Saravia 3,5\%; Oribe, Batlle y Luis Suárez: 3\%; Forlán y Tabaré Vázquez: 2\%; Mujica: 1,5\%, Benedetti: 1\%; e "Tupamaros" [sic], Sanguinetti y Seregni: 0,5\%. Estas listas compreendem os nomes que se repetiram no mínimo duas vezes, em um total de 508 casos e contando, também, com $28 \%$ de outros que aparecem só uma vez, em que se encontram Rada, Benedetti, meus pais, operários, Lolo Estoyanoff, 
Batman, entre outros, além de uma grande diversidade de casos entre o criativo, o original e o curioso.

Na continuação, mostra-se uma análise detalhada das opções que foram apresentadas pelos estudantes, com base nos critérios expostos anteriormente. Em primeiro lugar, pode-se observar que o ranking individual destaca a importante maioria relativa de menções para Artigas, com relação aos restantes, já que triplica a quem lhe segue na sequência, José Pedro Varela.

Entre os estudantes que colocaram algum herói, José Artigas obteve $30 \%$ das menções, com a particularidade de que, se somente for considerada a primeira coluna, ou seja, o primeiro herói em importância, Artigas têm $63 \%$ das escolhas.

Figura 1 - Menções de heróis nacionais uruguaios* (em porcentagem)

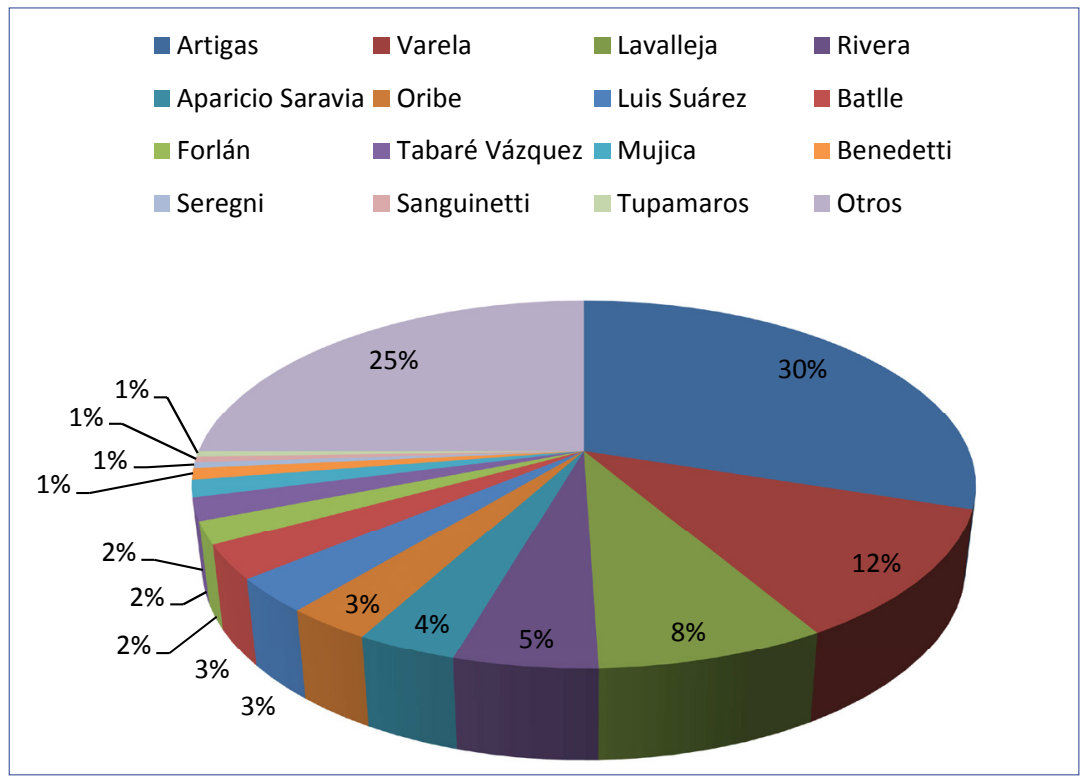

Fonte: dados do projeto Jovens e a História (2013). Elaboração dos autores.

* Entre os estudantes que preencheram pelo menos um dos nomes solicitados

O segundo mais nomeado foi José Pedro Varela, com 11\%; depois, Lavalleja com $8 \%$ do total. Como se analisa posteriormente, a figura de 
Artigas possui um caráter quase de onipresença simbólica nos uruguaios, e seu caso merece uma análise específica, que transcende uma mera nota de concordância, entre uma história oficial ensinada e um resultado destacado de seu lugar na enquete.

Em relação aos outros heróis que lhe seguem na ordem de indicações, podemos realizar algumas considerações. José Pedro Varela $\left(\mathrm{n}^{\circ} 2\right)$ foi o autor da reforma escolar de 1877, promovendo o ensino gratuito e obrigatório que, após a sua prematura morte enquanto exercia o cargo de Director Nacional de Educación Pública, passou a integrar o panteão nacional de forma permanente.

Sua imagem está em todas as escolas públicas, os cadernos e boletins de notas escolares levam seu retrato na capa e, no Uruguai, falar de educação vareliana constitui um valor-saber conhecido e predominante, que se associa aos pilares da educação republicana, gratuita, universal e laica.

Portanto, os dois primeiros heróis do ranking estão relacionados a figuras de dimensão nacional, que não tem claramente uma identificação partidária. Artigas teve sua atuação política antes que os partidos tradicionales existissem, e Varela foi ministro durante um governo militar de escasso perfil partidário.

No terceiro e quarto lugar apareceram duas referências históricas dos partidos tradicionales (colorados, com Rivera no $\mathrm{n}^{\mathrm{0}} 4$; e blancos, com Lavalleja em $3^{\circ}$ ) que, ao mesmo tempo, formaram parte dos exércitos revolucionários de Artigas e que, posteriormente, protagonizaram as primeiras presidências e golpes de estado de vida independente, dando origem aos bandos políticos tradicionais. Casualidade ou não, Lavalleja, que foi um líder na luta pela independência contra o Império do Brasil, em 1825, mas que nunca conseguiu chegar a ser Presidente (embora tenha tentado legalmente e também através de levantes armados), sempre aparece nas colunas 2 ou 3 , mas nunca em primeiro lugar. Parece ser um integrante do panteão que sempre acompanha, mas que não é visto como líder.

Em um terceiro nível do panteão, aparecem Oribe (fundador do partido blanco) e duas figuras da última guerra civil (1903-1904) e dos inícios 
do Uruguai moderno, do século XX: José Batlle e Ordoñez, do partido Colorado; e Aparicio Saravia, do blanco.

Agrupando os heróis, observa-se um predomínio das figuras tradicionais, indicadores do padrão clássico. Juntando as citações a personagens correspondentes ao panteão histórico (Artigas, Varela, Lavalleja, Rivera, Oribe, Batlle e Saravia), chegam a 63\% do total. Enquanto a segunda categoria que lhe segue em nomeações é a dos jogadores de futebol (com Luis Suárez liderando, mesmo ainda não jogando no Barcelona), que chega a $11 \%$ do total. Os políticos com atuação no presente alcançam 7\%, e representantes da cultura obtém $5 \%$ das indicações.

Observando a lista completa, os nomes, suas repetições e hierarquias, podemos confirmar um viés tradicional/ nacional e político na hora de mencionar heróis, desde o olhar de uma enquete sobre ensino da História realizado em diversos colégios.

\section{PADRÕES DE RESPOSTAS OBSERVADOS: CLÁSSICOS, FUTEBOLÍSTICOS E POLÍTICOS}

Sobre os padrões de reposta combinada, atrevemo-nos a distinguir alguns casos que, por reiterados, dão ideia de uma forma de conceber a heroicidade por parte de diferentes grupos dos consultados.

1. Em primeiro lugar, temos as respostas clássicas, aquelas que, em todos os casos, mencionam figuras políticas históricas vinculadas ao panteão histórico nacional e partidário. Neste caso, a combinação Artigas-Varela resulta ser a mais habitual, e recolhe entre os legados da construção simbólica nacional: ao prócer (Artigas) e ao fundador da escola pública (José Pedro Varela). Também aparecem mencionados os líderes originários dos partidos tradicionais (Rivera, Oribe, Lavalleja), ou figuras relevantes da guerra civil de 1904 (Aparicio Saravia, blanco; e Batlle, colorado). Quando todas as respostas têm algum dos mencionados, podemos afirmar que estamos ante uma resposta clássica. 
2. Em segundo lugar, temos as respostas culturais/futebolísticas. Casos nos quais o participante da enquete optou por marcar a destacados futebolistas ou atores da cultura (cantantes, pintores, escritores), evitando cair na resposta clássica, sem mencionar líderes políticos do panteão histórico nacional.

3. Em terceiro lugar, encontramos respostas politicamente recentes, em que o herói escolhido corresponde a personalidades da política dos anos 1960 até os dias atuais: Raul Sendic, Liber Seregni, Julio María Sanguinetti, José Mujica, Tabaré Vázquez, Luis Alberto Lacalle e Wilson Ferreira Aldunate. Esses casos nunca aparecem em estado puro, pois sempre estão acompanhados de outro tipo de líderes correspondentes aos padrões anteriores.

Por último, é importante destacar que existe um variado número de respostas combinadas, em que se misturam o clássico com o futebol, Artigas com os políticos atuais ou cantores com heróis do passado. As análises dessas combinações estão na parte seguinte deste texto.

\section{RESPOSTAS POR ALUNO}

Considerando o total de alunos (228) que responderam a enquete, os resultados observados foram os seguintes:

Tabela 1 - Respostas por aluno

\begin{tabular}{l|c|c}
\hline & Casos & $\%$ \\
\hline Artigas & 142 & 62,3 \\
\hline Panteão (sem considerar Artigas) & 124 & 54,4 \\
\hline Futebol & 38 & 16,7 \\
\hline Políticos recentes & 32 & 14 \\
\hline Cultura & 24 & 10,5 \\
\hline
\end{tabular}

Fonte: Dados do Projeto Jovens e a História (2013). Elaboração dos autores. *Entre os estudantes que preencheram pelo menos um dos nomes solicitados.

Como os estudantes podiam responder até três heróis, as combinações muitas vezes se agregam e, por isso, as porcentagens da tabela somam mais de 100 . 
Um olhar geral apresenta que quase dois terços dos estudantes colocaram Artigas como herói e, mais da metade, respondeu com figuras históricas do panteão tradicional. O fator mais reiterado pelos estudantes foi escrever Artigas; depois, outras figuras do panteão e, finalmente, acompanhar com alguns esportistas. Somente aparecem, ocupando o terceiro lugar, os jogadores do futebol, mas um quinto dos estudantes os menciona.

Figura 2 - Menções de heróis nacionais uruguaios* (em porcentagem)

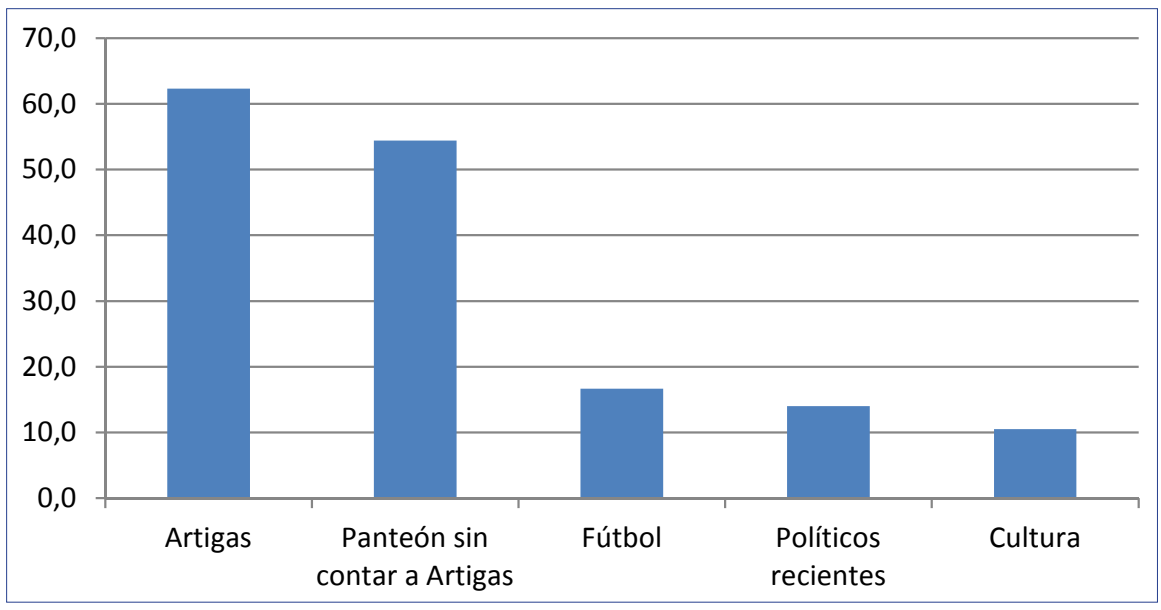

Fonte: Dados do Projeto Jovens e a História (2013). Elaboração dos autores.

*Entre os estudantes que preencheram pelo menos um dos nomes solicitados.

Agrupando os tipos de repostas em todos os casos como Panteão, Futebol, Políticos Recentes ou Cultura, o segundo herói que mais aparece junto é, mais uma vez, a figura de Artigas; ou seja, entre aqueles que escolheram futebolistas, a maioria dos outros mencionados correspondeu para Artigas, e o mesmo aconteceu em outros casos. Sendo assim, percebemos a confirmação de um nítido predomínio de Artigas em primeiro lugar e o histórico-oficial em segundo plano que, somados, diferenciam-se com distância do resto dos heróis.

Percebemos, então, que o terceiro grupo é o de futebolistas, com um viés predominantemente masculino. Ainda, não figuram, entre as preferências, cantores de músicas populares mais recentes, ou estrelas da mídia adolescente. As figuras da cultura mencionadas, no geral, correspondem a 
personalidades do mundo adulto (Mario Benedetti e Idea Vilariño são poetas da chamada Generación de 1945) ou cantores de reconhecimento internacional (como Ruben Rada na Argentina, ou Jorge Drexler na Espanha, e pela obtenção do Oscar de melhor canção no ano de 2005). Com a exceção de duas ocasiões em que são mencionados grupos de rock, todas as vezes, os personagens da cultura podem ser associados com o sentido de completar a enquete de forma séria (e, porque não, um pouco chata?).

Confirma-se, assim, a impressão inicial, de que os estudantes colocam-se em situação de responder uma enquete para a disciplina de História em um âmbito formalizado desde o escolar e que, provavelmente, guardaram seus ídolos juvenis por considerá-los menos formais ou não tão nacionais.

Devemos agregar, ainda, que uma dificuldade a mais para que isto aconteça é que, no Uruguai, a indústria midiática é economicamente muito fraca e, por isso, muitas das estrelas são figuras internacionais da mídia televisiva, o que deixa ainda mais difícil de serem associados com heróis da história nacional.

No entanto, o futebol país constitui uma forte senha de identidade e uma grande escala de visibilidade internacional; então, alguns jogadores de futebol podem ser entendidos como resposta aceitável para heróis. Um esportista de destaque que nos represente (assim fala-se na mídia, como embaixadores do Uruguai) e, ainda mais, que realizem suas atividades de sucessos na própria Seleção Nacional.

Vários autores (PIÑEYRÚA, 2014; MORALES, 2014) têm analisado o componente cultural/indenitário do futebol e sua relação com as desigualdades sociais e a adolescência, tratando-se de uma das primeiras opções laborais ou de carreira que muitas famílias uruguaias consideram como possível e desejável para o futuro de seus filhos. Sendo até provável, neste sentido que, para os jovens de 15 anos que escolheram futebolistas, essa realidade pessoal tenha influenciado. Por outra parte, em um país pequeno, essa atividade esportiva, que consegue presença e visibilidade internacional, constitui-se em um fator de orgulho nacional e de reconhecimento. Além de momentos melhores ou piores, o futebol tem constituído um dos exemplos de mais longa duração, considerando, também, que a enquete foi realizada 
depois da conquista da Copa América 2011, realizada na Argentina, e da quarta colocação na Copa do Mundo da África do Sul, em 2010.

Por isso, este grupo de estudantes da enquete apresenta um sentido de heroísmo desportivo nacionalista recente, com uma única exceção que chama atenção e até apresenta um aspeto simpático: um jovem citou Alcides Edgardo Ghiggia (autor do segundo gol na final de Maracanã na copa de 1950), provocando dúvida, entre os pesquisadores, se deveria ser contabilizado como parte das respostas do futebol ou do Panteão. Considerando estes comentários gerais sobre os outros tipos de respostas, minoritários, devemos lembrar e sublinhar o predomínio do clássico, historicamente esperável. Na segunda parte, aportamos reflexões para compreender um resultado tão conservador e reiterado.

\section{OS VÁRIOS HERÓIS POR TRÁS DA FIGURA DE ARTIGAS}

As imagens de Artigas, como herói nacional, transcendem amplamente a História ensinada em nível secundário, e relacionam-se diretamente com uma cultural histórica prévia e que contextualiza sua figura, que é utilizada como referência em diversas instâncias de formação de opinião e construção de imaginários coletivos.

A presença de Artigas, destacada entre os jovens uruguaios consultados, tem pouca relação com a História que se ensina dentro das escolas, pois a temática da revolução hispano-americana e oriental está presente somente no segundo ano. Não ocupa um lugar central nos currículos, já que aparece entre as últimas unidades do programa oficial e, também, é muito provável que, em muitos casos, os alunos tenham vivenciado poucas aulas sobre o período revolucionário.

Desta forma, encontramo-nos com um tipo de resposta majoritariamente relacionada com uma atitude do dever ser, muito mais do que com um resultado de aprendizagens historiográficas próprias das aulas. Isto Permite apresentar algumas características em relação à construção de Artigas, muito além das salas de aula, na qual participam desde atores políticos, com visões ideológicas distintas, até a publicidade de marcas de erva mate que utilizam sua imagem. 
Discursos em que desaparecem as aporias e os debates de o político, apresentam-se e constituem-se como um discurso neutro. Por isto, é importante se questionar: Quem é o Artigas que os jovens escolheram? Aquele do discurso romântico nacionalista? O neutro do pensamento Ilustrado? O conveniente da boa resposta escolar, dentro da lógica memorialística de uma visão de mundo unificada e exemplar? O Artigas uruguaio ou o herói regional? Quantas diferenças se escondem por trás da aparente homogeneidade de Artigas?

Estas reflexões permitem lembrar a importância de considerar que a disciplina História não gera somente problemas para o campo educativo ou cognitivo, mas dentro construção formativa de identidades nas novas gerações, tanto no campo político, social e, também, cultural para agir no mundo.

\section{OS DISCURSOS ANTERIORES À FRENTE AMPLIO}

Um bom exemplo para ver esta criação do múltiplo Artigas à la carte são os discursos pronunciados em homenagens, nos atos oficiais, a cada 19 de junho (dia do natalício do prócer), quando governava o Partido Colorado em aliança com parte do Partido Nacional (Blanco). Pode-se observar uma geração de sentido da história que se identifica com o tradicional, partindo de narrativas oficiais. Por exemplo, Alfonso Varela, no ano 2000, sendo Ministro de Turismo no governo de Jorge Batlle Ibañez, foi o orador principal em representação do Poder Executivo. Em sua oratória, afirmou que "Cada generación tiene su Artigas. Como si éste hubiera construido un medio puente hacia cada uno de nosotros y nos hubiera déjalo la posibilidad de construir la otra mitad". Essa primeira parte da ponte marca uma continuidade, em que a segunda deve ser encaixada de forma imutável e linear.

Querendo falar sobre a Guerra Fria e os conflitos políticos nos anos 60 no Uruguai, começa afirmando que a primeira metade da ponte foi quando Artigas combateu dois impérios (Espanha e Portugal) que, "tras San Ildefonso y Tordesillas se habian repartido el mundo... Nuestra tierra oriental fue uno de los límites de esos dos imperios", para depois finalizar a engenharia da obra edilícia: 
La realidad mundial en 1960 y 1970 era similar a la época de Artigas. Dos grandes naciones dominaban el mundo... Nuestro país no fue ajeno a esa lucha. Nos olvidamos del ideario artiguista. Nos enfrentamos oriental contra oriental. Se defendieron modelos e ideas que no eran los nuestros. (VARELA, 2000) ${ }^{1}$

Devemos ter presente que, no dia 21 de março do ano 2000, foi reconhecida a verdadeira identidade de Macarena Gelman (neta do poeta Juan Gelman e filha de detidos-desaparecidos), quebrando a ideia sustentada durante muitos governos do pós-ditadura, que negavam a existência de casos de crianças sequestradas e desaparecidas no Uruguai. O sentido principal do discurso resulta da pretensão de orientar o presente, a partir de uma determinada visão do passado, que outorga mais informação sobre o orador e sobre a imagem que determinado grupo quer ter de si, mesmo que sobre o próprio Artigas. O modo exemplar da consciência histórica, como afirma Cerri (2011, p. 101), é resultado de apresentar ao passado:

[...] como um conjunto de exemplos, cuja função é reforçar as regras gerais de conduta predominantes em determinada sociedade. A articulação entre passado, presente e futuro acontece em função da contínua validade dessas regras. No passado são encontrados os modelos a seguir de modo a dominar o presente e estabelecer o futuro.

Será, novamente, essa pretendida continuidade essencialista que levou ao Ministro Industria, Mineria e Energia Pedro Bordaberry, como orador principal no ato do ano 2002, a afirmar que:

El lugar es el mismo, pero la realidad no. Lo que no quiere decir que no haya situaciones similares puesto que la región y el País siguen siendo parecidos... todos seguimos buscando las mismas cosas que buscaba Don José. Y enfrentando problemas parecidos (BORDABERRY, 2002).

Em relação aos problemas que o país enfrentava no início do século XIX, insiste a ideia de essência imutável: "Curiosos designios los del destino que nos coloca en similares situaciones y nos hace reaccionar de manera parecida. Es que la realidad es distinta pero la situación geopolítica es similar" (BORDABERRY, 2002). Esta perene situação permite, como já tinha sido feito pelo Ministro Varela, afirmar que

\footnotetext{
${ }^{1}$ Os discursos dos atos comemorativos do 19 de junho foram extraídos da página oficial da presidência da República Oriental del Uruguay no período 2000-2005.
} 
Artigas también vivió la lucha de dos imperios que tomaron esta tierra oriental como escenario para dirimir sus conflictos. Los peleó a los dos... Hace algún tiempo volvimos a ser escenario de confrontación. Otros eligieron este lugar como escenario... los muros y las ideologías cayeron, pero quedaron heridas abiertas, de ambos lados (BORDABERRY, 2002).

A consciência histórica, como uma estrutura do pensamento humano, apresenta-se nestes discursos não somente como uma estrutura exemplar, também com um sentido tradicional onde "as origens são postas como uma obrigação para com o futuro. O conteúdo da tradição, nesse caso, é tomado como um dado natural e certo, sobre o qual não existe ou não cabe reflexão ou questionamento" (CERRI, 2011, p. 101).

Artigas configura-se, para esta visão, como a representação da neutralidade, da objetividade e da laicidade no ensino da história nacional. A política parece desaparecer no nome do prócer; no entanto, o político realiza intensas disputas para ocupar o espaço simbólico do conceito Artigas, procurando apropriar-se de seu prestígio. Nestes discursos comemorativos do 19 de junho, a figura política dilui-se em uma hagiografia absolutamente desinteressada sobre o passado, mas muito interessada na eficiência prática, como "peça de propaganda: de verdadeira arma no combate aos hereges" (DOSSE, 2015, p. 145). Suas virtudes são encarnações humanas do sagrado (neste caso vinculado com a Pátria) que, como descreve François Dosse (2015, p.139), propõem uma lenda para gerar identificação, aderência e imitação. Vale lembrar que a origem do conceito de lenda remete à ideia de aquilo que é para ler em liturgias, em atos oficiais, em comemorações.

A didática da História tem, como um de seus trabalhos principais, analisar as variações da utilização destes heróis e, no caso concreto de Artigas, os diversos sentidos que se vinculam a sua figura, na mistura entre o santo laico e o herói. Na fabricação de heróis, a necessária incompletude (a media ponte do Ministro Varela) ressalta o princípio de transcendência que faz com que "cada época cria seus heróis e lhes atribui, quer sejam de uma época distante, próxima ou atual, seus próprios valores. O herói, cristaliza em si uma simbolização coletiva..." sempre disputado (DOSSE 2015, p. 151).

No ano 2001, o responsável da oratória oficial no ato cívico foi o Ministro de Educação e Cultura, Antonio Mercader, integrante do Partido 
Nacional. Em um contexto extremamente sensível, somente dois meses após ser anunciado que o agronegócio uruguaio sofria com focos de febre aftosa, afetando o centro da economia nacional. Neste clima, o Ministro declarou que

Vivimos en tiempos de dificultades, si es verdad, pero ¿no eran acaso tiempos mucho más difíciles los que vivió Artigas dos siglos atrás cuando ni patria había y cuando la amenaza de la intervención extrajera se cernía sobre el país? (MERCADER, 2001).

Sendo tempos de dificuldade, o exemplo de superação que deve ser observado "cuando sobrevienen, una tras otra, las contrariedades, los problemas, las acechanzas... (es) la continuidad de un proyecto que nació aquí, en estas tierras, hace 237 años" (MERCADER, 2001).

\section{O ARTIGAS QUE DEVE SER}

Com sua entrega suprema aos valores da Pátria, particularmente em momentos de adversidade, Artigas é apresentado como o mártir de um coletivo singular, mas a identificação com a nação requer, também, o reconhecimento e a participação dos que aceitam ou não essa relação. Nos discursos dos políticos em atos oficiais, existe um Artigas que pretende ser o modelo para identificar o autenticamente uruguaio, principalmente através de juízos de tipo moral, em que o herói ainda não foi laicizado.

Porém, o Artigas que os estudantes escolhem é único e sagrado, ou resulta de uma construção que permite aprender a pensar o passado, atribuindo diferentes significados, superando modelos exemplares ou tradicionais? Porque, o que está em jogo não é somente a imagem do herói, mas o debate sobre uma didática da História que se pretende dialógica na construção de identidades que abram a possibilidade de aprender a pensar o passado como encruzilhadas de caminhos. Evitando admitir, sem debates nem argumentos, que a forma que se impõe foi a única possível, abrindo, assim, a oportunidade de pensar, também, diversas formas de futuro.

A história oficial é transmitida com conteúdos racionais e emotivos, como algo instituído que deve ser seguido como já é e, para isto, utiliza as imagens de heróis como 
Un verdadero movimiento de sacralidad donde el martirio, en el sentido cristiano, se transforma en martirio por causa de la Patria. Semejante sacrificio presupone la instauración de toda una pedagogía de solidaridad nacional. Con ese propósito, se retoma el antiguo modelo de la Historia Magistrae, de la vida ejemplar de quien entregó su sangre y que existe como figura simbólica de una deuda indefinida, contraída por la comunidad por la cual se sacrificó voluntariamente. La educación y la transmisión del pasado son entonces concebidas de forma explicitas, por sus representantes, como instrumentos que recuerdan la deuda de las nuevas generaciones con sus ancestrales (DOSSE, 2015, p. 179).

No mesmo discurso no ano de 2001, Antonio Mercader afirmou que

Es bueno tener presente las lecciones de nuestra historia por eso la enseñamos en las escuelas y liceos. Por eso es tan importante insistir en que la historia nacional debe enseñarse en profundidad par que nos sirva de guía y para que nos guie y para que nos diga quiénes somos, de dónde venimos, hacia dónde vamos (MERCADER, 2001).

Insiste, portanto, na visão da história como magister vitae, exemplar e tradicional, resultado de um espaço de experiência supostamente contínuo na retórica e na moral. Essa questão introduz o debate sobre a laicidade ${ }^{2}$ no ensino da História, porque

Algunos han querido ver en esta inquietud un presunto ataque al principio de la laicidad. ¡No es así!... Nadie quiere que se adoctrine en una religión, pero jatención! tampoco queremos que se adoctrine en favor de una determinada corriente política. Politizar la enseñanza, aprovechar la cátedra para hacer proselitismo político, es una actitud altamente condenable que ser señalada y combatir. Esta es una de nuestras preocupaciones centrales... (MERCADER, 2001).

A história escolar que se apresenta como neutra e objetiva, sustentada nos fatos do passado, tem uma particularidade adicional, no caso uruguaio, através dos debates sobre a violação da laicidade. Aqui surge um problema, ou melhor, até um não problema, porque a pretensão de neutralidade e de objetividade são problemáticas no sentido de discutíveis, confrontáveis, e os debates sobre a laicidade carregam o paradoxo de ser semirreligiosos.

No entanto, basta lembrar o extenso debate sobre o ensino da História recente (2005 a 2008), em que o principal argumento dos opositores é que o

\footnotetext{
${ }^{2}$ Para o caso italiano, Gentile (2007, p. 18) analisa que "La laicización de la sociedad consistía en producir una unidad moral de los ciudadanos inculcando en su ánimo, los 'dogmas de la religión civil', el sentido del deber cívico y la obediencia al estado".
} 
tema trabalhado nas aulas consistiu em denunciar a violação da laicidade. Este tipo de conceito conservador de um ensino da história laica obedece a uma definição que, desde a política, nega o viés aporético do político, e determina que o Estado deve ser o lugar do neutro. Trata-se de uma história que tem como função descrever modelos (muita ênfase na moral) e nunca restituir problemas (ROSANVALLON, 2003), escondendo a lógica contraditória de denunciar uma politização nas escolas, desde uma hiperpolitização oficial.

Em relação à análise dos resultados dos heróis nacionais, percebemos maioritária presença deste Panteão Laico, que mantém intacta a aparência de uma constante natural com a figura de Artigas, secundada pelas restantes figuras que "son representados como sus hijos más dilectos" (DI GIORGI, 2014, p. 46).

As historiadoras Isabela Cosse e Vania Markarian realizararam um estudo sobre a consciência histórica uruguaia, publicado em livro no ano de 1994, que gera um nós coletivo e que marca uma identificação com o ser uruguaio na "[...] capacidad de reconocer un determinado pasado como pasado común y la de proyectarse al futuro son, entonces, requisitos básicos para la existencia de una comunidad nacional" (COSSE; MARKARIAN, 1994, p. 42). No estudo ${ }^{3}$ aparece uma consciência histórica nacional, elaborada de consensos, principalmente através de dois sustentos unificadores: José Artigas e os Partidos Tradicionais como forjadores da nação. A figura de Artigas aparecia como o personaje más admirado de la historia nacional, com $63 \%$ das opções e as autoras interrogavam:

¿Qué dice de una colectividad el hecho de que no vacile en rendir admiración unánime a una única figura histórica? Habla de una sociedad de consensos, que integra las diferencias y que amortigua los disensos... el artiguismo es quizás la zona más firme de la conciencia histórica nacional. El lugar común de las diferencias en las coincidencias, donde convergen las diversas interpretaciones de la historia y del destino nacional donde contenidos diferentes adoptan un mismo nombre" (COSSE; MARKARIAN 1994, p. 58-59) ${ }^{4}$.

\footnotetext{
${ }^{3}$ En total plantearon 281 cuestionarios semi-estructurados a la población montevideana entre 18 y 65 años con educación primaria completa.

${ }^{4}$ Destacam como caso oposto uma investigação realizada no Peru, onde nenhum personagem superou $13 \%$ dos votos.
} 
Outra operação historiográfica sobre a construção da identidade nacional está vinculada com os dois denominados Partidos Tradicionales, que "han sido, junto con el sistema educativo, los mediadores en la multiplicidad de lecturas académicas y la sociedad, jugando así un papel determinante en la conformación de la consciencia histórica nacional" (COSSE; MARKARIAN 1994, p. 62). É desde o Estado, e também desde os partidos políticos, que fundamentalmente tem-se gerado a produção de sentidos que determinam o que é historicamente correto, o que é racional, o tolerante, o nacional e, principalmente, o laico. Disto resulta que a incorporação da história recente nas aulas gerou um alarme em relação às ideias de sentido comum na sociedade uruguaia.

Resulta inquietante que a figura de Artigas mantenha a constante de uma porcentagem similar de aprovação (mais de 60\% nas primeiras preferências dos estudantes consultados em nosso estudo), com a diferença de que se trata de novas gerações e em um contexto político diferente, com a esquerda governando pela segunda vez consecutiva. De modo que, muito além de ser uma realidade atribuível a concepções sobre o objetivo e os consensos, a figura de Artigas persiste como imagem simbólica primária, acima das mudanças políticas e geracionais.

Pode se tratar de uma continuidade nas formas de ensino e na concepção básica do que é a história escolar, mas é indispensável confirmar elementos de longa duração na cultura, que permitam entender porque Artigas segue sendo escolhido, quando a história oficial já não está dirigida pelos partidos tradicionais. Provavelmente sua condição de líder nacional sem vínculo com aqueles Partidos e a identificação da maioria da esquerda com o pensamento artiguista seja chave para compreender sua extensão simbólica acima das mudanças políticas.

\section{OUTROS ARTIGAS: ENCONTROS E DESENCONTROS}

O historiador José Rilla, em seu trabalho La actualidad del Pasado (2008), destaca que entre a escola e os Partidos definem-se a identidade nacional. Se a política supõe conflito e discórdia, esta sociedade, como muitas outras, armou os conflitos ao redor dos partidos e encontrou, em 
Artigas, um lugar de concórdia e acordos, trabalhosamente construído como centro de uma religião cívica: "para la historia un genio, para la patria un Dios" diz o hino escolar. Esta centralidade política de Artigas, em todo o século XX, permitiu criar um terreno de afinidade entre os dois principais partidos políticos, que reuniam mais de $90 \%$ do eleitorado. No entanto, como afirma Rilla,

La concordia colorada y blanca en torno al prócer (que no había sido blanco ni colorado) se vio desafiada cuando la izquierda unificada en el Frente Amplio asaltó la ciudadela artiguista en la que ambos bandos habian depuesto sus armas [...] Líber Seregni, líder del Frente Amplio en 1971 diría "...el Frente Amplio es el legítimo heredero de la tradición artiguista y toma sus banderas e ideario (RILLA, 2008, p. 235).

Quando o bipartidarismo tradicional foi questionado e entrou em crise com o surgimento de uma colisão de esquerdas (Frente Amplio), a figura de Artigas não foi questionada, mas resinificada também, desde aquele setor ideológico. Como narra Jaime Yaffé (2001, p. 412, grifos do autor),

A la leyenda "negra" perpetrada por los vencedores de 1820, le sucedió la leyenda de "bronce" inaugurada a fines del siglo XIX por los primeros historiadores uruguayos como conveniente revisión de la anterior... multiplicado por miles y miles gracias a la pasión por el bronce desplegada por las autoridades, emergió como elemento de orgullo y religión nacional.

As transformações político-ideológicas foram acompanhadas de mudanças na produção historiográfica porque, como afirma Yaffé (2001, p. 425, grifo do autor),

La segunda mitad del siglo XX conoció una creciente hostilidad hacia el bronce legendario (...) pero limitado a sus dotes políticas y militares. La historiografía más dinámica de los agitados años sesenta encaminó una nueva visión del artiguismo que acentuó atributos humanos del caudillo, sus preocupaciones sociales y económicas, su inclinación por los más "infelices".

Essa transformação coincidiu com a criação de uma "nueva y vigorosa identidad política: el frenteamplismo" (Yaffé, 2001, p. 412). A esquerda uruguaia se auto percebia como a autêntica superação do tradicionalismo, representado por blancos e colorados, mas a criação do frenteamplismo e sua fusão com os "outros Artigas" (social, económico, cultural, latinoamericanista), gerou uma "verdad invención de tradición" (Yaffé, 2001, 
p. 415) e um reposicionamento da esquerda no leque da cultura política nacional, abandonando a distância com as tradições, e respondendo à acusação de ser estrangeira.

"Padre Artigas, guíanos" foi o grito de encerramento do primeiro discurso de Líber Seregni como candidato do Frente Amplio, no ano de 1971, para apresentar ao artiguismo como um projeto inconcluso, que

La izquierda utilizará para proclamarse a sí misma no solo como la continuación histórica del artiguismo traicionado, sino también como síntesis y prolongación de las tradiciones blanca y batllista al tiempo que acusaba a los partidos tradicionales de haberlas abandonado y con los que la izquierda se identifica (YAFFÉ, 2001, p. 419).

Assim, a esquerda uruguaia, além de criticar e fazer oposição aos Partidos Tradicionais, tentou nacionalizar-se e tradicionalizar-se através da figura de Artigas, com um discurso de traição ou projeto inacabado. De novo, a metade da ponte, com o mesmo nome, mas com outro sentido.

Existem, assim, diversas percepções, amplamente maioritárias, e mesmo contraditórias, que situam Artigas como seu herói, seja a partir de uma perspectiva nacionalista, oficialista, militar ou de esquerda. Por isso, não resulta surpreendente que, mais de vinte anos depois da pesquisa de Cosse e Markarián (1994), em que 7 (sete) de cada 10 (dez) uruguaios consideravam erradas as críticas contra Artigas, os atuais resultados da enquete entre os estudantes seja coincidente.

Os contextos não são os mesmos: naquele momento, governava o Partido Nacional, que tentava aplicar reformas de caráter liberal na economia, quando o país ingressava no Mercosul. No ano de 2011, o Uruguai encontrava-se com um segundo governo consecutivo da Frente Amplio, desta vez liderado pelo ex-guerrilheiro, José Mujica, e um conjunto de políticas sociais de integração regional muito marcantes. E em ambos contextos, Artigas foi amplamente majoritário.

Para um jovem, integrante de uma família que votou em Mujica, em 2009, a figura de Artigas não gera rejeição, porque o Pepe autodenomina-se como artiguista, fala em Pátria Grande, em defender aos mais infelizes, etc. Mas o mesmo acontece em uma família blanca, que associa Artigas com 
o nacionalismo; ou de uma colorada, que possui um perfil mais próximo com a lenda de bronze, da imagem de Artigas prócer oficial. Isto porque a aprendizagem histórica não fica restringida às aulas escolares, e as relações e contradições entre os discursos da agenda social e política e os desafios no ensino da história escolar geram encontros e desencontros. O conceito de consciência histórica, desenvolvido por Jörn Rüsen, torna-se relevante para pensar a relação entre esse espaço público e a formação histórica escolar e, também, os vínculos entre o saber histórico e o agir cotidiano, sendo

[...] o conjunto das competências de interpretação do mundo e de si próprio, que articula o máximo de orientação do agir com o máximo de autoconhecimento, possibilitando assim o máximo de auto-realização ou de reforço identitário [...]. Formação opõe-se criticamente à unilateralidade, à especialização restritiva e ao afastamento da prática e do sujeito (RÜSEN 2007, p. 95).

Assim, a relação com os heróis e a formação histórica não podem ser pensadas como um campo fixo de orientações temporais que a pessoa tem, mas como resultado sempre inconcluso de uma construção narrativa e dialógica de cada sujeito, que questiona e reelabora os discursos oficiais e os periféricos, que disputam as narrativas do dever ser. A história ensinada e aprendida nas escolas e o pensar historicamente que os professores promovem nas escolas sobre o tempo, as identidades e as narrativas de uma história nacional e seus heróis estão em constante diálogo e, muitas vezes, contrapostos com a proposta construída com uma geração de sentido de tipo tradicional e exemplar, que

Tiende a valorar positivamente al propio grupo social, explicar sus características en términos esencialistas y no histórico, rechazar las fuentes que ponen en conflicto una versión complaciente de la propia historia, valorar en términos positivos la evolución politica del país, recuperar en forma acrítica el rol de ciertos personajes históricos emblemáticos, en muchas ocasiones a través de la dicotomía "héroes y villanos", y tender lazos de permanencia y continuidad entre los hechos y personajes del pasado y la actualidad del grupo nacional (CARRETERO; CASTORINA, 2012, p. 12, grifos dos autores).

Uma didática da História que assume os professores e os estudantes como sujeitos ativos e críticos na construção da meia ponte, relacionada com o presente e com o futuro, considera central o: 
doble movimiento de aprendizaje, el pasaje del dato objetivo a la apropiación subjetiva, $y$ de la búsqueda subjetiva de afirmación al entendimiento objetivo, alcanza el nivel o la calidad de la formación cuando consigue concretar la articulación entre objetividad y subjetividad del pensamiento histórico, característica de la historia como ciencia" (RÜSEN, 2007, p. 108).

A relação entre heróis, didática da História e consciência histórica gera desafios e reflexões relevantes para o ensino da História que, desde suas origens, esteve vinculada à produção e reprodução da identidade nacional, suspendida em um mítico presente contínuo, entre um estudante consumidor passivo e um professor reprodutor de informações.

Essa história deve ser questionada como formadora de identidades não razoáveis e míticas ${ }^{5}$, em oposição ao diálogo entre sujeitos, em palavras de Luis Fernando Cerri (2011, p. 113).

não se trata de um racionalismo cartesiano, em que a verdade está em algum lugar somente, e não está em outros, e nem um racionalismo relativista, em que a verdade, por estar com todos, não existe. Tratamos de uma razão comunicativa ou dialógica, que não é absoluta nem relativa, mas relacional, ou seja, a verdade se constitui no diálogo entre sujeitos [...].

A história e os heróis descem do pedestal para ser discutidos, debatidos e não impostos, como desejaria uma didática obediente de transmissão e absorção. Sendo assim, a perduração de Artigas pode ser entendida como uma transformação de significados, desde uma perspectiva que incorpore a dialética entre a longa duração cultural, até as transformações políticas/ geracionais recentes. Mais do que uma figura imutável, a perenidade de Artigas e suas diversas significações falam de mudanças e de continuidades.

\section{REFERÊNCIAS}

BORDABERRY, Pedro. Discurso pronunciado en el acto oficial del 19 de junio del 2002. Secretaria de prensa y difusión de la Presidencia de la ROU. 2002.

\footnotetext{
${ }^{5}$ Como ejemplo podemos recordar que en la Alemania de 1934 se publica una bibliografía de Simón Bolivar, donde en el prólogo se fija la posición de la política alemana de la época: "Justamente hoy, cuando el principio de liderazgo se ha abierto paso en Alemania, el destino de un dirigente y los conocimientos que ha adquirido durante su agitada vida el libertador y redentor de un continente, deben despertar especial interés" (WERZ, 1991, p. 104).
} 
Disponível em: http://www.presidencia.gub.uy/noticias/archivo/2002/ junio/2002061901.htm. Acesso em 24 jan. 2004.

CARRETERO, Mario; CASTORINA, José. La construcción del conocimiento histórico. Enseñanza, narración e identidades. $2^{\mathrm{a}}$ reimp. Buenos Aires, Paidós, 2012.

CERRI, Luis Fernando. Ensino da história e consciência histórica. Implicações didáticas de uma discussão contemporânea. Rio de Janeiro. Editora FGV, 2011. COSSE, Isabela; MARKARIAN, Vania. Memorias de la historia. Una aproximación al estudio de la conciencia histórica nacional. Montevideo, Ediciones Trilce, 1994.

DI GIORGI, Álvaro Sanguinetti. La otra historia del pasado reciente. Montevideo, Fin de Siglo, 2014.

DOSSE, François. O desafio biográfico. Escrever uma vida. $2^{\mathrm{a}}$ ed. São Paulo, Editor da USP, 2015.

GENTILE, Emilio. El culto del Littorio: la sacralización de la política en la Italia fascista. Buenos Aires: Siglo XXI editores, 2007.

MERCADER, Antonio. Discurso pronunciado en el acto oficial del 19 de junio del 2001. Secretaria de prensa y difusión de la Presidencia de la ROU, 2001. Disponível em: http://www.presidencia.gub.uy/noticias/archivo/2001/ junio/2001061902.htm. Acesso em: 24 jan. 2004.

MORALES, Andrés. Fútbol e identidad Rioplatense. Ediciones de la Biblioteca Nacional, Cuadernos de Historia. Montevideo, 2014.

PIÑEYRÚA, Ricardo. El fútbol y otros deportes. Ediciones del Bicentenario. Montevideo, 2014.

RILLA, José. La actualidad del pasado. Usos de la historia en la política de partidos del Uruguay (1942-1972). Debate. Montevideo, 2008.

ROSANVALLON, Pierre. Por una historia conceptual de los político. México DF. FCE, 2003. 
RÜSEN, Jorn. História viva. Teoria da história III: formas e funções do conteúdo histórico. Editora da UnB. Brasília, 2007.

VARELA, Alfonso. Discurso pronunciado en el acto oficial del 19 de junio del 2000. Secretaria de prensa y difusión de la Presidencia de la ROU, 2000. Disponível em: http://www.presidencia.gub.uy/noticias/archivo/2000/ junio/2000061901.htm. Acesso em: 24 jan. 2004.

WERZ, Nikolaus. Reflexiones sobre la imagen de Bolívar y la enseñanza de la historia en Venezuela. In: RIEKENBERG, Michael (comp.) Latinoamérica: enseñanza de la historia, libros de texto y consciencia histórica. Buenos Aires, Alianza Editorial/ Flacso/ Georg Eckert Instituts, 1991.

YAFFÉ, Jaime. La izquierda uruguaya y el pasado revolucionario oriental ¿Una leyenda roja del artiguismo?. In: FREGA, Ana e ISLAS, Ariadna. Nuevas Miradas en torno al artiguismo. Facultad de Humanidades, Universidad de la República. Montevideo, 2001. 